\title{
An examination of authentic leadership as an individual and social factor of resilience
}

DOI 10.2478/jms-2021-0015

Received: February 21, 2021; Accepted: August 26, 2021

\begin{abstract}
Resilient qualities, which derive from protective factors, enable an individual to balance exposure to vulnerabilities in military service and throughout life. Protective factors arise from within an individual, from social factors, and from an individual's environment. Research on social factors, such as strong leadership and peer relationships, continues to emerge and significantly relate to resilience. Of specific interest to organisations is how perceptions of leadership contribute to resilience as an individual and social protective factor. Knowing more about how soldiers perceive themselves on authentic leadership and resilience would better help researchers and practitioners understand the contribution of leadership on perceived resilience. The current study examined the perception of authentic leadership in self and first-line leaders with resilience in a population of 179 soldiers $(N=179$; $M=26.86$ years, $S D=6.42$ ). The results noted a significant correlation between the perception of authentic leadership in oneself and resilience $(r=0.506, p<0.001)$. A subsequent analysis examining the perception of authentic leadership in one's first-line leader and subordinate resilience was also significant $(r=0.394, p<0.001)$, supporting previous findings. These results demonstrate that perceptions of leadership matter as an individual and social factor in military personnel.
\end{abstract}

Keywords: protective factors, leadership styles, social influence, military, resilience

\section{Introduction}

Soldiers in the U.S. Army are frequently exposed to high levels of stress and adversity across the span of military service that includes training, operational deployments and combat (Bartone 2006). Hence, the ability to

\footnotetext{
*Corresponding author: John W. Gaddy, Magellan Federal, E-mail: Jgaddy4@kennesaw.edu

Stephen P. Gonzalez: Dartmouth College, Hanover, New Hampshire
}

respond during adversity is an essential component for mission accomplishment and sustained success in military service (U.S. Army 2012). The U.S. Army defines resilience as 'the mental, physical, emotional, and behavioral ability to face and cope with adversity, adapt to change, recover, learn and grow from setbacks' (U.S. Army 2014, p. 6). Resilience includes personal qualities and cognitive abilities that allow one to successfully function following exposure to adversity (Galli and Gonzalez 2015). It is a multidimensional construct of psychological and dispositional variables such as hardiness (Bartone et al., 2016; Eid et al., 2008; Escolas et al., 2013), grit (Duckworth and Quinn 2009), self-efficacy (Galli and Vealey 2008), social support (Mandleco and Perry 2000) and lived experiences that combine uniquely to form one's level of resilience (Luthar et al., 2000).

\subsection{Protective factors and vulnerabilities}

Psychological or dispositional attributes that impact resilience can originate from within an individual, from social interactions and from the environment (Masten et al., 1990). These attributes can be categorised as protective factors and vulnerabilities. Protective factors refer to those which enhance positive adaptation following adversity (Straus et al., 2019), while vulnerabilities are factors which increase the likelihood of maladaptation to adversity (Lee et al., 2013). The same factor can be either a protective or a vulnerability based on the context and interaction with the individual. For instance, self-efficacy is a personal judgement on how well a person can cope (Bandura 2006). This personal judgement can be either a protective or vulnerability factor, depending on the outlook of the person in combination with life experiences and countless other variables. Social interactions can equally be protective, through nurturing experiences with others, or maladaptive, through degrading or toxic associations. The complex balancing act between protective factors and vulnerabilities points to the dynamic nature of increasing protective factors as a counterweight to vulnerabilities to maintain a healthy psychological homeostasis. 
In addition to the possibility of a factor being protective or maladaptive, extant research has noted the differences in the relative strength of the variables on resilience (Lee et al., 2013). Some personal traits (e.g. extroversion, agreeableness, conscientiousness, negative emotionality, open mindedness) or cognitive qualities can to be more impactful than others in the development of resilience (Smith et al., 2013). Context plays a role in how impactful traits and qualities are, as illustrated by the growing research on resilience in a multitude of areas such as education, sports and medicine. This relative variability indicates a need for researchers to explore the different variables on resilience and assess that are most related towards positive responding following periods of adversity in certain contexts.

\subsection{Authentic leadership as a social factor of resilience}

Social support and social relationships include family, friends, coworkers, subordinates, peers and leaders from across an individual's personal environment. Positive social relationships provide tangible resources to enhance the ability to cope with adversity and can serve as a buffer for negative impacts on psychological resilience (McCabe et al., 2020). Comparatively, poor social relationships can be deleterious on one's ability to cope with adversity if the relative weight of vulnerabilities outweighs protective factors. One social factor of resilience with significant implications for military personnel is the role of unit members and leadership (Adrian et al., 2018).

Leadership researchers have explored the relationship between leadership styles and subordinate behaviours for decades (Bass and Bass 2008). Many studies focus on specific leader actions or attributes and the outcomes on subordinates. While unique in design and results, a review of the extant literature indicates the influential role leaders have on the actions and behaviour of subordinates (Avolio and Gardner 2005; Hannah et al., 2020; Vanhove et al., 2016; U.S. Army 2012). Harland et al. (2005) noted the relationship between leadership based on positive psychology and psychologically resilient behaviours. If positive psychology-based practices enhance resilience, leadership styles based on positive psychology could be an effective vehicle for strengthening the ability to respond repeatedly following adverse situations (Harland et al., 2005).

Authentic leadership can be defined as a pattern of leader behaviour that leverages and promotes positive psychological capacities to foster greater self-awareness, internalised moral perspective, balanced processing and relational transparency (Baron and Parent 2015; Walumbwa et al., 2008). Authentic leadership promotes positive psychological interactions and an ethically sound organisational climate (Hirst et al., 2016). Self-awareness represents how accurately one sees their own values, aspirations, beliefs and reactions (Eurich 2018). Relational transparency represents the authentic presentation of one's self to others (Baron and Parent 2015). Balanced processing is defined as the objective analysis of data in decision-making (Zehir and Narcikara 2016). Internalised moral perspective represents the self-regulation of one's conduct consistent with internal values rather than from external sources, including social expectations (Walumbwa 2008). In sum, authentic leadership behaviours enable subordinates to develop confidence in their leaders through trust, hence providing critical support to challenges encountered in adverse environments and situations.

Authentic leadership has been previously researched in military contexts as a factor in resilience. Research by Gaddy et al. (2017) demonstrated a positive relationship between perceptions of authentic leadership and resilience in subordinate infantry soldiers. While this finding is promising, more research on the construct of authentic leadership in military populations is vital for understanding how leadership and contribute to resilience as a social protective factor.

\subsection{The present study}

The general topic with which the present study is concerned is how the perception of leadership influences resilience. Focusing on the resilience factor of social support, Harland et al. (2005) determined that views on leadership are related to resilience. This relationship has the potential for positive or negative outcomes on resilience (McCabe et al., 2020). To increase the body of knowledge on the relationship between leadership and resilience, especially in military populations, this study was designed to explore the perception of leadership in self and as a social factor in relation to resilience. Specifically, the researchers asked, 'What is the relationship between one's self-reported authentic leadership with their own resilience as an individual factor' and aimed to provide a replication of previous work (Gaddy et al., 2017) regarding the question, 'What is the relationship between the perception of authentic leadership in first-line leaders and subordinate resilience as a social factor?' 


\section{Method}

A secondary data analysis is the exploration of existing data originally collected by Weston et al. (2019) for a different purpose. They note that secondary analysis is a suitable method for conducting either correlational or experimental research. Adherence to a systematic process for secondary analysis is an effective option when conducting empirical research (Johnston 2017). Additionally, in populations where data collection is generally limited or difficult to conduct, such as military populations, secondary analysis of data can be useful for researchers seeking preliminary insights into a population. The foundation of a secondary data analysis is to apply theoretical and conceptual knowledge using existing data to address the research questions. The current study followed the systematic process described by Johnston (2017) in which researchers (1) determine the research questions, (2) identify the data set originally approved by an Institutional Review Board and (3) evaluate the data set.

\subsection{Source of data set}

Data originated as a component of a larger grant-funded study. Data from the original study were provided to the authors with the specific purpose of conducting this secondary analysis to explore the relationship between psychological resilience and leadership. The purpose of the original study was to examine the role of mindfulness on working memory and attention in a military cohort. The study was conducted at Fort Stewart, Georgia in 2015 and data collection occurred in a quiet room on the military installation. All participants were administered a battery of computerised cognitive tasks and self-report questionnaires. Participants completed the battery in groups of up to 18 and were proctored by a team of two or three experimenters. The testing session required approximately $2 \mathrm{~h}$ to complete all items. The data for the present study were administered as components of the total assessment battery and were not analysed in relation to each other as a part of the larger study.

\subsection{Participants}

All participants in this study were U.S. Army active-duty soldiers $(N=179 ; M=26.86$ years, $S D=6.42)$. The original collection began with 180 soldiers, but 1 participant was removed from the analysis for failure to complete
Tab. 1: Ethnicity, race, military rank and gender of study participants

\begin{tabular}{|c|c|c|}
\hline Measure & $N$ & $\%$ \\
\hline \multicolumn{3}{|l|}{ Ethnicity } \\
\hline Not Hispanic or Latino & 140 & 78.21 \\
\hline Hispanic or Latino & 18 & 10.05 \\
\hline Unknown or not reported & 21 & 11.73 \\
\hline \multicolumn{3}{|l|}{ Race } \\
\hline American Indian & 3 & 1.65 \\
\hline Asian & 7 & 3.91 \\
\hline African American & 66 & 36.87 \\
\hline Hispanic & 14 & 7.82 \\
\hline Caucasian & 76 & 42.45 \\
\hline Other & 13 & 7.26 \\
\hline \multicolumn{3}{|l|}{ Rank } \\
\hline E-1 PVT & 1 & 2.23 \\
\hline $\mathrm{E}-2 \mathrm{PV} 2$ & 14 & 7.82 \\
\hline E-3 PFC & 38 & 21.22 \\
\hline $\mathrm{E}-4 \mathrm{SPC}$ & 78 & 43.57 \\
\hline E-5 SGT & 23 & 12.84 \\
\hline E-6 SSG & 13 & 7.26 \\
\hline E-7 SFC & 4 & 2.23 \\
\hline E-8 MSG & 2 & 1.11 \\
\hline $0-12 \mathrm{LT}$ & 1 & 0.55 \\
\hline $0-21 \mathrm{LT}$ & 1 & 0.55 \\
\hline $0-3$ CPT & 1 & 0.55 \\
\hline Self-report gender female & 47 & 26.25 \\
\hline Self-report gender male & 132 & 73.74 \\
\hline
\end{tabular}

the demographic assessment. Table 1 presents the demographics of ethnicity, race, military rank and self-reported gender. All participants in the initial study provided informed consent in compliance with a university Institutional Review Board and governmental oversight provided by the U.S. Department of Defense Human Research Protections Office. No soldiers participating in this study received any compensation in addition to their military salary in accordance with the Department of Defense regulations governing soldier compensation. All involvement occurred during the normal duty day. A group-randomised assignment strategy was used for selecting participants to maintain the organic structure of different military units. As scheduling active-duty cohorts can be challenging, this methodology is consistent with other military studies (e.g. Adler et al., 2008; Jha et al., 2020). Personal identifying information was removed from the 
raw data and was not provided for use in the present study to ensure participant confidentiality.

\subsection{Measures}

The Authentic Leadership Questionnaire (ALQ) asked respondents questions about their perceptions of authentic leadership in self and in their first-line leader on a scale of 0-4 (Walumbwa et al., 2008). The ALQ is a 16-item questionnaire that includes four subscales, assessing self-awareness (4 items, e.g. My leader accurately describes how others view his or her capabilities), relational transparency ( 5 items, e.g. My leader admits mistakes when they are made), internalised moral perspective (4 items, e.g. My leader makes decisions based on his or her core values) and balanced processing (3 items, e.g. My leader analyses relevant data before coming to a decision). The ALQ includes a self-version and a rater-version. Both include the same questions, but the self-version uses 'I' and the rater-version uses 'my leader' to begin each survey question.

The Connor Davidson Resilience Scale (CD-RISC) measures the ability to respond following adversity on a scale of 0-4 (Connor and Davidson 2003). The CD-RISC consists of 25 questions assessing resilience (e.g. I try to see the humorous side of things when I am faced with problems). The CD-RISC does not separate questions into sub-factors and combines all 25 responses into one score. Higher scores on the scale indicate a greater level of resilience.

\section{Data analysis}

The Statistical Package for Social Sciences (SPSS 26) was used to conduct all correlational and regression analyses. The relationship between authentic leadership and subordinate resilience was analysed by first calculating the mean survey scores and standard deviations for the CD-RISC and the ALQ. The ALQ included the self- and rater-versions to measure perceptions in the individual and first-line leader factors. CD-RISC scoring included the sum of the full 25-item scale (Connor and Davidson 2003). The full 16-item ALQ scale was summed to produce a higher order score (Walumbwa et al., 2008). A Pearson correlation was calculated to analyse whether a positive or negative correlation between (1) the perception of authentic leadership in self with resilience and (2) the perception of authentic leadership in one's first-line leader with resilience. Multiple regression analysis was conducted using the predictor variables of the perception of authentic leadership in self, the perception of authentic leadership in the first-line supervisor, time in service and military rank to determine the strength of each variable on resilience.

Factor analysis serves to group similar variables into a factor to identify the underlying variables for analysis in the data correlation matrix. A factor analysis was conducted to ensure that the components of each questionnaire measured the perception of authentic leadership appropriately. A separate analysis was conducted for the ALQ-Self-version and the ALQ-Rater-version. Principal component analysis was conducted to assess the self and leader version of the ALQ. For each version, four factors were used based on the instrument design of selfawareness, balanced processing, internalised moral perspective and relational transparency. The CD-RISC was not included in this factor analysis because only one score was provided for the CD-RISC from the original researchers for use in this secondary analysis. A scree plot was conducted to graphically present the point where factor reduction should be stopped. Only one factor was extracted on both versions of the ALQ with Varimax rotation and therefore, the solution could not be rotated for either scale. A correlation matrix within the factor analysis was produced and factors less than 0.3 were omitted (Shrestha 2021). The Kaiser-Meyer-Olkin test results measuring sampling adequacy on the ALQ-Self were 0.82 and for the ALQ-Rater they were 0.86 , which exceeds the acceptable value of 0.60 (Shrestha 2021). A Barlett's Test of Sphericity results measuring factorability of the correlation matrix on the ALQ-Self and the ALQ-Rater were both measured as $p<0.001$. These results support the factor grouping of the results on both the ALQ versions and the appropriateness of using these measures for the purposes described in this study.

\section{Results}

The current study examined the perception of authentic leadership in self and first-line leaders with resilience via the ALQ-Self $(N=179 ; M=12.13$ score, $S D=2.20)$, the ALQ-Rater $(N=179 ; M=10.71, S D=3.97)$ and the CD-RISC $(N=179 ; M=75.13$ score, $S D=14.35)$ (Table 2). The results illustrate a significant correlation between the perception of authentic leadership in oneself and resilience $(r=0.506$, $p<0.001)$. A replication analysis examining the perception of authentic leadership in one's first-line leader and 
Tab. 2: Descriptive statistics of the ALQ-Self and ALQ-Rater with CD-RISC

\begin{tabular}{lccccccc}
\hline Measure & $\boldsymbol{N}$ & Minimum & Maximum & Mean & SD & $\boldsymbol{r}$ & \multicolumn{1}{c}{$\boldsymbol{\alpha}$} \\
\hline ALQ & 179 & 6.33 & 16.00 & 12.13 & 2.20 & $0.506^{\star \star}$ & -81 \\
CD-RISC & 179 & 38.00 & 100.00 & 75.13 & 14.35 & - & 0.87 \\
ALQR & 179 & 0.20 & 16.00 & 10.71 & 3.97 & $0.394^{\star \star}$ & 0.94 \\
\hline
\end{tabular}

${ }^{* \star}$ Correlation is significant at the 0.01 level (2-tailed).

ALQ, Authentic Leadership Questionnaire; ALQR, Authentic Leadership Questionnaire-Rater; CD-RISC, Connor Davidson Resilience Scale.

Tab. 3: Coefficients, confidence interval and collinearity

\begin{tabular}{|c|c|c|c|c|c|c|c|c|c|}
\hline \multirow[b]{2}{*}{ Variable } & \multirow[b]{2}{*}{ B } & \multirow[b]{2}{*}{ Std. error } & \multirow[b]{2}{*}{$\beta$} & \multirow[b]{2}{*}{$t$} & \multirow[b]{2}{*}{ Sig. } & \multicolumn{2}{|c|}{$95 \%$ confidence interval for B } & \multicolumn{2}{|c|}{ Collinearity statistics } \\
\hline & & & & & & Lower bound & Upper bound & Tol. & VIF \\
\hline 1 Constant & 28.851 & 5.621 & & 5.133 & 0.000 & 17.757 & 39.944 & & \\
\hline ALQ & 2.852 & 0.429 & 0.434 & 6.651 & 0.000 & 2.006 & 3.698 & 0.904 & 1.107 \\
\hline ALQR & 0.941 & 0.237 & 0.260 & 3.975 & 0.000 & 0.474 & 1.408 & 0.902 & 1.109 \\
\hline Rank & 0.571 & 0.583 & 0.061 & 0.980 & 0.329 & -0.580 & 1.722 & 0.993 & 1.007 \\
\hline TIS & -0.141 & 0.165 & -0.054 & -0.857 & 0.393 & -0.466 & 0.184 & 0.988 & 1.013 \\
\hline
\end{tabular}

Dependent variable: CD-RISC-T1.

ALQ, Authentic Leadership Questionnaire; TIF, Time in Service; VIF, Variance Inflation Factor.

subordinate resilience also noted significance $(r=0.394$, $p<0.001$ ) that supported previous findings (Gaddy et al., 2017). As an ad hoc measure, the relationship between ALQ-Self and ALQ-Rater was also significantly related $(r=0.287, p<0.001)$.

\subsection{Variables of military rank and years of service on resilience}

A multiple regression on resilience assessed four predictor variables and calculated significance levels as authentic leadership in self $(p<0.001)$, authentic leadership in firstline supervisor $(p<0.001)$, military rank $(p=0.329)$ and years in service $(p=0.393)$. The overall regression model was significant $(r=0.57, F(4.174)=p<0.001)$. The multiple linear regression calculated a beta weight to the statistically significant variables of the perception of authentic leadership in self $\left(\beta_{\text {authentic leadership }}=0.434, p=0.000\right)$ and the perception of authentic leadership in their first-line supervisor $\left(\beta_{\text {authentic leadership rater }}=0.260, p=0.000\right)$.

\section{Discussion}

The purpose of this study was to expand the existing body of knowledge on the relationship between psychological resilience and one's perception of authentic leadership in both self and their first-line leader. In addition, the replication of previous findings on the topic of authentic leadership and resilience strengthens the understanding of this construct. Improving the resilience of leaders and soldiers requires training to prepare service members for the complex and demanding experiences required of a soldier (U.S. Army 2018). To meet this expectation for training soldiers to become more resilient, the U.S. Army implemented the Master Resilience Trainer program designed to train soldiers in 12 resilience skills annually (U.S. Army 2014). While highly valuable, a complementary focus on bolstering authentic leadership behaviours could reinforce the current training efforts across the force (Table 3). Building resilience within the military can be amplified by holistically strengthening individual thinking styles, but should also leverage the wide array of social protective factors found within organisational groups.

Authentic leadership could be a productive model for leadership development training in any organisation because of the specificity on the four sub-factors of self-awareness, relational transparency, internalised moral perspective and balanced processing. If a leader wants to strengthen the resilience of their organisation, developing a culture that values each of the four sub-factors has been shown in this study to be related with resilience. While not causal, authentic leadership behaviours examined in this work are positively related to resilience. Further research 
on this topic could improve the ability to generalise these findings to the greater population.

The lack of statistical significance in the exploration of time in military service and rank adds to the pool of knowledge on the predictors of resilience. These findings suggest that all personnel are impacted by their perception of authentic leadership. Building authentic leader behaviours can be an effective medium for optimising resilience regardless of time in service or military rank.

\subsection{Replication of previous findings}

Appelbaum et al. (2018) explain that an external replication occurs when a researcher reports a replication of one or more previously published studies. When reporting a replication, it is important to compare the original and the replication with enough detail to allow for appropriate evaluation. Specifically, details on participants, conditions, measures, methods or otherwise should be presented to allow for the comparison of findings (Appelbaum et al., 2018).

The original study (Gaddy et al., 2017) examined the perception of authentic leadership with subordinate resilience. Respondents $(N=132)$ were all active-duty soldiers assigned to Fort Stewart, Georgia. The administration of the survey data was via paper and ink in a comfortable waiting room on the installation. The measures used were the CD-RISC and ALQ-Rater-version only. The method of analysis was to sum both surveys to establish a higher order score, then conduct a Pearson correlation to determine whether a positive or negative correlation existed. The original study noted a significant positive relationship ( $r=0.41, p<0.005)$. The current study supported these replicated findings with similar results $(r=0.39$, $p<0.005)$. A lack of significance was noted in the demographic variables of military rank and years in service in both studies.

\section{Limitations}

A significant limitation of this study was the correlational design that inherently cannot demonstrate a causal relationship. While a relationship between authentic leadership and resilience was noted in this study, the potential for confounding variables or other uncontrolled factors could not be minimised when evaluating this data. A second limitation of this study is the lack of direct interaction with the data collection process. To offset this limitation, the researchers used raw documentation from the original study free of analysis when available. In addition, multiple consultations with the original researchers strengthened the understanding of data for use in the current study. Third, the survey results provided for the purpose of this research only included data that were summed into one total score for the CD-RISC. As a result, this research does not include a factor analysis on the CD-RISC, which is a best practice for contemporary empirical research. Fourth, a limitation of this research is grounded in the cross-sectional design of the study. A cross-sectional study observes a population at a specific point in time. A cross-sectional study commonly uses survey data as in the current study, but does not include multiple measurements across time points. This single snapshot in time limits the ability to declare a cause-andeffect relationship between variables. Finally, the potential exists that one's resilience could impact how they see others. Specifically, an individual who exhibits high levels of optimism may see their leaders in a more favourable light. Their view on the world around them may be coloured through a strongly optimistic lens that causes leaders to appear more transparent, self-aware, moral and balanced in processing.

\section{Conclusion}

This study extends the understanding of psychological resilience and specifically how one's views on leadership are related to the ability to respond effectively following adversity. The exploration of authentic leadership as an individual factor and as a social factor of resilience emphasises the importance of leadership in the ability of individuals to respond productively following adversity. A significant correlation between the perception of authentic leadership in oneself with resilience $(r=0.506$, $p<0.001)$ and the perception of authentic leadership in one's first-line leader with resilience $(r=0.394, p<0.001)$ demonstrates the influential nature that leadership can have on psychological resilience. Indeed, when one self-reports authenticity in their behaviours (self-reported authentic leadership), this allows for resilience to potentially occur as well as allow for a superior to be viewed as authentic. The continued exploration of individual and social factors attributing to the development of resilience has the potential to identify the most valuable antecedents in the development of one's response following adversity. 


\section{Acknowledgements}

The authors would like to thank the members of the U.S. Army who participated in this study and the lab of Dr. Amishi Jha for providing data originally collected in support of a Department of the Army grant \#W81XWH-12-2-0051.

\section{Disclosure statement}

No potential conflict of interest was reported by the authors.

\section{Funding}

The authors received no financial support for the research and authorship of this article.

\section{Biographies}

John W. Gaddy is a Regional Manager with Magellan Federal and a part-time Assistant Professor of Organizational Leadership at Kennesaw State University. He served over 20 years in the U.S. Army and his research is focused on understanding the psychological demands of military service.

Stephen P. Gonzalez is the Assistant Athletic Director for Leadership and Mental Performance at Dartmouth College. He is a former Professor of sport psychology and a U.S. Army Contractor. His research is focused on psychological resilience, emotion and leadership in performance contexts.

\section{References}

Adler, A. B., Litz, B. T., Castro, C. A., Suvak, M., Thomas, J. L., Burrell, L., McGurk, D., Wright, K. M., \& Bliese, P. D. (2008). A group randomized trial of critical incident stress debriefing provided to U.S. peacekeepers. Journal of Traumatic Stress, 21(3), pp. 253-263. doi: 10.1002/jts.20342.

Adrian, A. L., Adler, A. B., Thomas, J. L., \& Britt, T. W. (2018). Integrating new soldiers: The role of leaders and unit members. Military Psychology, 30(2), pp. 131-141.

Appelbaum, M., Cooper, H., Kline, R. B., Mayo-Wilson, E., Nezu, A. M., \& Rao, S. M. (2018). Journal article reporting standards for quantitative research in psychology: The APA Publications and Communications Board task force report. American Psychologist, 73(1), pp. 3.

Avolio, B. J., \& Gardner, W. L. (2005). Authentic leadership development: Getting to the root of positive forms of leadership. The Leadership Quarterly, 16(3), 315-338. doi: 10.1016/j.leaqua.2005.03.001.

Bandura, A. (2006). Guide for constructing self-efficacy scales. Self-efficacy Beliefs of Adolescents, 5(1), pp. 307-337.

Baron, L., \& Parent, É. (2015). Developing authentic leadership within a training context: Three phenomena supporting the individual development process. Journal of Leadership \& Organizational Studies, 22(1), pp. 37-53. doi: $10.1177 / 1548051813519501$.

Bartone, P. T. (2006). Resilience under military operational stress: Can leaders influence hardiness? Military Psychology, 18(sup1), pp. 131-148. doi: 10.1207/s15327876mp1803s_10.

Bartone P. T., Valdes, J. J., \& Sandvik, A. (2016). Psychological hardiness predicts cardiovascular health. Psychology, Health \& Medicine, 21(6), pp. 743-749, doi: 10.1080/13548506.2015. 1120323.

Bass, B. M., \& Bass, R. (2008). The Bass Handbook of Leadership: Theory, Research \& Management Applications, 4th edn. New York, NY: Free Press.

Connor, K. M., \& Davidson, J. R. (2003). Development of a new resilience scale: The Connor-Davidson resilience scale (CD-RISC). Depression and Anxiety, 18(2), pp. 76-82. doi: $10.1002 /$ da.10113.

Duckworth, A. L., \& Quinn, P. D. (2009). Development and validation of the Short Grit Scale (GRIT-S). Journal of Personality Assessment, 91(2), pp. 166-174.

Eid, J., Johnsen, B. H., Bartone, P. T., \& Nissestad, O. A. (2008). Growing transformational leaders: Exploring the role of personality hardiness. Leadership \& Organization Development Journal.

Escolas, S. M., Pitts, B. L., Safer, M. A., \& Bartone, P. T. (2013). The protective value of hardiness on military posttraumatic stress symptoms. Military Psychology, 25(2), pp. 116-123. doi: $10.1037 /$ h0094953.

Eurich, T. (2018). What self-awareness really is (and how to cultivate it). Harvard Business Review. Available at https://hbr. org/2018/01/what-self-awareness-really-is-and-how-to-cultivate-it

Gaddy, J. W., Gonzalez S. P., Lathan, C.A., \& Graham, P. K. (2017). The perception of authentic leadership on subordinate resilience. Military Behavioral Health, 5(1), pp. 64-72. doi: 10.1080/21635781.2016.1243495.

Galli, N. \& Gonzalez, S. P. (2015). Psychological resilience in sport: A review of the literature and implications for research and practice. International Journal of Sport and Exercise Psychology, 13(3), pp. 243-257. doi: 10.1080/1612197X. 2014.946947.

Galli, N. \& Vealey, R. S. (2008). “Bouncing back” from adversity: Athletes' experiences of resilience. The Sport Psychologist, 22(3), pp. 316-335. Available at http://journals.humankinetics. com/tsp

Hannah, S. T., Perez, A. L., Lester, P. B., \& Quick, J. C. (2020). Bolstering workplace psychological well-being through transactional and transformational leadership. Journal of Leadership \& Organizational Studies, 27(3), pp. 222-240. doi: $10.1177 / 1548051820933623$.

Harland, L., Harrison, W., Jones, J. R., \& Reiter-Palmon, R. (2005). Leadership behaviors and subordinate resilience. Journal of Leadership \& Organizational Studies, 11(2), pp. 2-14. doi: $10.1177 / 107179190501100202$ 
Hirst, G., Walumbwa, F., Aryee, S., Butarbutar, I., \& Chen, C. J. H. (2016). A multi-level investigation of authentic leadership as an antecedent of helping behavior. Journal of Business Ethics, 139(3), pp. 485-499.

Jha, A. P., Zanesco, A. P., Denkova, E., Morrison, A. B., Ramos, N., Chichester, K., Gaddy, J.W., \& Rogers, S. L. (2020). Bolstering cognitive resilience via train-the-trainer delivery of mindfulness training in applied high-demand settings. Mindfulness, 11(3), pp. 683-697.

Johnston, M. P. (2017). Secondary data analysis: A method of which the time has come. Qualitative and Quantitative Methods in Libraries, 3(3), pp. 619-626.

Lee, J. H., Nam, S. K., Kim, A. R., Kim, B., Lee, M. Y., \& Lee, S. M. (2013). Resilience: A meta-analytic approach. Journal of Counseling \& Development, 91(3), pp. 269-279.

Luthar, S. S., Cicchetti, D., \& Becker, B. (2000). The construct of resilience: A critical evaluation and guidelines for future work. Child Development, 71(3), pp. 543-562. doi: 10.1111/14678624.00164.

Mandleco, B. L., \& Perry, J. C. (2000). An organizational framework for conceptualizing resilience in children. Journal of Child and Adolescent Psychiatric Nursing, 13(3), 99-111. doi: 10.1111/ j.1744-6171.2000.tb00086.x.

Masten, A. S., Best, K. M., \& Garmezy, N. (1990). Resilience and development: Contributions from the study of children who overcome adversity. Development and Psychopathology, 2(4), pp. 425-444.

McCabe, C. T., Watrous, J. R., \& Galarneau, M. R. (2020). Trauma exposure, mental health, and quality of life among injured service members: Moderating effects of perceived support from friends and family. Military Psychology, 32(2), pp. 164-175. doi: 10.1080/08995605.2019.1691406.

Shrestha, N. (2021). Factor analysis as a tool for survey analysis. American Journal of Applied Mathematics and Statistics, 9(1), pp. 4-11.
Smith, B. N., Vaughn, R. A., Vogt, D., King, D. W., King, L. A., \& Shipherd, J. C. (2013). Main and interactive effects of social support in predicting mental health symptoms in men and women following military stressor exposure. Anxiety, Stress \& Coping, 26(1), pp. 52-69.

Straus, E., Norman, S. B., Tripp, J. C., Pitts, M., \& Pietrzak, R. H. (2019). Purpose in life and conscientiousness protect against the development of suicidal ideation in US military veterans with PTSD and MDD: Results from the National Health and Resilience in Veterans Study. Chronic Stress, 3, pp. 1-10. doi: $10.1177 / 2470547019872172$.

U.S. Army. (2012). Army leadership. Army Doctrine Publication 6-22. Washington, DC: Headquarters, Department of the Army.

U.S. Army. (2014). Comprehensive soldier and family fitness. Army Regulation 350-53. Washington, DC: Headquarters, Department of the Army.

U.S. Army. (2018). The U.S. Army in multidomain operations 2028. TRADOC Pamphlet 525-3-1. Fort Eustis, VA: Headquarters, Department of the Army Training and Doctrine Command.

Vanhove, A. J., Herian, M. N., Perez, A. L., Harms, P. D., \& Lester, P. B. (2016). Can resilience be developed at work? A meta-analytic review of resilience-building program effectiveness. Journal of Occupational and Organizational Psychology, 89(2), pp. 278-307.

Walumbwa, F. O., Avolio, B. J., Gardner, W. L., Wernsing, T. S., \& Peterson, S. J. (2008). Authentic leadership: Development and validation of a theory-based measure. Journal of Management, 34(1), 89-126. doi: 10.1177/0149206307308913.

Weston, S. J., Ritchie, S. J., Rohrer, J. M., \& Przybylski, A. K. (2019). Recommendations for increasing the transparency of analysis of preexisting data sets. Advances in Methods and Practices in Psychological Science, 2(3), pp. 214-227. doi: $10.1177 / 2515245919848684$.

Zehir, C., \& Narcıkara, E. (2016). Effects of resilience on productivity under authentic leadership. Procedia-Social and Behavioral Sciences, 235, pp. 250-258. 